\title{
Employment of the 'Peer Feedback' Technique in L2 Writing Classrooms: An Introductory Guide for Novice Instructors
}

\author{
Suliman Mohammed Nasser Alnasser \\ Department of English Language and Literature, College of Arts, King Saud University, Saudi Arabia
}

Copyright $\bigcirc 2018$ by authors, all rights reserved. Authors agree that this article remains permanently open access under the terms of the Creative Commons Attribution License 4.0 International License

\begin{abstract}
The development of writing skills in L2 contexts has been the focus of researchers over the last three decades with feedback (FB) receiving attention for the positive impact it can have on the learning process. The peer feedback technique (PF) is one tool employed by language instructors that has facilitated the provision of useful FB to learners. The technique has gained a positive reputation among language instructors, especially those focused on writing. Large numbers of studies have examined the effectiveness of the technique, with many reporting some learner concerns towards it and offering recommendations for making the most of this technique. It is, nevertheless, particularly necessary for instructors to become fully aware of how to properly employ this technique in order to avoid ending up with either negative results, or no results at all. This paper aims to provide writing instructors with a brief guide to effective use of the PF technique based on recommendations given by researchers and to facilitate effective practice for both instructors and learners.
\end{abstract}

Keywords Collaborative Writing, L2 Writing, Language Instruction, Language Learning, Peer Feedback

\section{Introduction}

In recent years, a large proportion of practitioners and researchers in second/foreign language writing have been exploring ways of engaging learners actively in the learning process in ways which can lead to better learning outcomes. The peer feedback technique (PF), as a collaborative learning technique, is one that has received most attention with various studies investigating its nature and what aspects promote greater impact on learning [11, 17, 18, 35, 45, 47]. Nevertheless, several of these studies have reported learner concerns regarding its nature [17], with some giving recommendations on how to maintain effective use of the technique in writing classes. It is our duty, therefore, as researchers in the field of L2 writing to review the literature and offer a brief guide for writing instructors on the use of PF in order to make the best use of the technique. From that perspective, this paper aims to provide a brief guide to what should be considered when employing PF technique and how to maintain effective use of the technique.

\section{Background}

\subsection{Feedback and Sociocultural Theory}

A number of researchers who have worked from a sociocultural theory perspective assert that learning languages is not limited to cognitive interaction with others, as it also involves social interaction [25, 36, 41]. Associating interaction with feedback can provide learners with opportunities for a positive impact on their linguistic, cognitive and social interaction skills [25]. At the heart of sociocultural theory exists Vygotsky's [43] concept of a Zone of Proximal Development (ZPD). The concept suggests that learners have domains that may not be reached without receiving assistance from others. In other words, the ZPD marks different levels of learning achievements with and without receiving assistance [4]. In that regard, FB is a method of providing assistance to learners and can be seen as a method of reinforcing learning - or scaffolding - which can lead to further improvement in, for example, the ability of learners to learn.

\subsection{Feedback and Language Learning}

Since the nineteen seventies, various researchers have investigated the relationship between FB and learning [5, 7, 
$8,9,15,24,37]$. Several subsequent studies were conducted to reach deeper insights into and effective approaches to providing FB. For example, one of the second language acquisition approaches that emerged was the 'focus-on-form' approach where the instructor provider of FB - provides FB mainly in the form of a written piece of text $[40,27]$. Schmidt [39] suggests that this approach can prove to be very effective in positively stimulating learning. The effectiveness of feedback on the learning process has been thoroughly investigated by several researchers [e.g., 13, 29, 30]. Most of these studies have identified a positive impact from FB on learning in areas such as: learning accuracy, improvement in linguistic skills and improvement in the learning process in general. It is argued that FB is an integral part of learning second/foreign languages in general and of writing development in particular [35]. Phuwichit [35] further explains that in order for learners to overcome their weaknesses and reinforce their points of strength, FB has to be offered.

In recent years, several studies have focused on FB aspects such as types of FB and peer feedback (PF). For language instructors, it is important to improve the way in which FB is provided. In writing classrooms in their current state - containing large numbers of students who require timely and effective FB on an individual basis- it is almost impossible for instructors to provide FB. Such limitations bring the peer feedback technique into light, a technique that has been recommended by several researchers as a fruitful potential solution. The following section discusses this technique to provide a rationale for its employment in writing classrooms.

\subsection{Peer Feedback: An Overview}

A brief survey of the literature shows that the most commonly used FB in writing classrooms is that provided by the teacher. Nevertheless, many teachers find a need to utilise other sources of FB in order to enhance the learning process. It has been proven that the PF technique is one of the more effective techniques commonly used in L2 writing instruction. Several researchers have empirically examined the technique and concluded by making recommendations for its employment $[18,45,47]$.

It is suggested that learners need to receive effective feedback that guides learners in different modes, allowing for interaction and producing responses [22]. This can be facilitated through a writing conference between two or more parties - teacher-student or student-student - where learners engage in negotiating meaning and attempt to interpret given feedback. In that regard, PF can allow for having such modes and can be seen as a way of producing learning benefits $[16,20]$. The benefits of the PF technique are because it involves learners working collaboratively and actively doing tasks such as reading and critiquing texts and then providing FB to their peers. Learners work in a scaffolding dynamic that allows them to receive immediate PF that can impact positively on their writing skills over time [19]. Furthermore, PF as an activity can allow peers to produce a high level of engagement in a collaborative work [38].

The PF technique can be defined as an activity that involves peers of similar status and produces a qualitative outcome [16]. Throughout the process, points of strength and weakness in a particular text are discussed by peers who eventually offer suggestions that can contribute to text quality. Some researchers may consider PF a counterpart of teacher feedback if learners are properly trained [46]. Additionally, Gielen et al. [16] argue that incorporating peer response in L2 learning is seen as crucial for success for learning.

In 2005, Rollinson [38] introduced an article that summarises the main arguments in favour and against the use of this technique and how to adapt effective procedures for creating a positive PF context. That summary has been widely appreciated by researchers and practitioners in particular. After reviewing the literature, however, it is seen that studies on PF have been accumulating which give new valuable suggestions that may lead to more effective use of the technique. In this situation, it may not be possible for each writing instructor to go through the studies one-by-one in order to become sufficiently aware of the most effective and up-to-date practice inside the classroom. The problem of not being familiar with how to present it to learners in an optimal manner may not yield the best outcomes. It is, therefore, the purpose of this paper to summarise the recommendations given by other studies in order to establish a platform for those who have partial knowledge of this area and need an express guide for establishing a proper context in which PF can be used to make greater positive change.

\subsection{Why Can Peers not Just Simply Exchange Essays and Comment?}

Instructors who do not have any experience of PF may introduce it to their learners simply as exchanging and commenting on each other's work. From the learner perspective, they may encounter difficult situations that can hinder their learning, leading them to hold concerns regarding this technique. For example, several studies reported learner reservations towards the quality of peer feedback they received, describing it as unreliable [46]. Such learner concern can become a barrier from accepting the PF they receive, which, if accepted, may lead to deterioration in their writing. It is, therefore, essential to become fully aware of how to deal with such concerns and properly introduce this technique to learners by taking into account what can be done and what should be avoided while it is practiced. In this manner, it can be ensured to some extent that there is encouragement of an active learning environment which is known to be crucial for 
learning. Furthermore, it is suggested that active learning has three main aspects [12]:

- Learner engagement in examining academic meaning.

- Allowing for greater learner responsibility in learning such as solving problems, thinking and negotiation with fellow learners.

- Encouraging learner skill acquirement and mastering the knowledge being studied.

These aspects of active learning can be promoted if an effective PF context is established and for effective use to be seen, several issues need to be considered. The following section will introduce key issues with regard to the PF technique.

\section{Issues of Consideration}

\subsection{Training in $\mathbf{P F}$}

Student-writers can produce effective, reliable and helpful PF to their fellow students, however, this is not likely without adequate training. Learners in many contexts may not experience active situations in which they participate positively in critiquing others, while the lack of such critiquing skills when experiencing PF situations may lead to PF of low quality. After examining the technique, several researchers questioned the effectiveness of the technique and how learners can produce PF of high quality, with Min [32] reporting that an average of only thirty nine per cent of PF produced is likely to be accepted. This is a result of learners lacking critical skills. Some of the studies explain that training into how to use the technique is a key tool to raise peer feedback quality and will lead to acceptance. Min, for example, conducted several studies investigating how training can lead to the production of high-quality PF that is likely to be accepted by other peers.

According to that study, systematic training had a significant positive impact on learners, in that they produced peer feedback of high quality that was seen by the participants as more reliable. It is appropriate at this juncture to briefly describe what training procedures the participants went through in order to allow the reader to form a clear concept of how similar training can be carried out.

In-class modelling [32]: Before peer reviewing first drafts and before those participants can practice this technique, they need to be provided with samples of written texts - possibly written by previous students. The teacher can then use the think-aloud method to demonstrate to learners loudly how comments should be provided in an optimal manner. This can be done by adopting the following steps: "clarifying writers' intentions (e.g., do you mean...? are you saying...?), identifying the source of problems, explaining the nature of problems (why it is problematic), and finally, making specific suggestions" [6, p. 56]. When the demonstration is complete, the teacher can allow learners to practice giving FB by critiquing the texts they were given and observing the process. It is necessary to ensure that learners follow the given procedures when critiquing the texts. If any of the steps are not clear, the teacher needs to re-demonstrate it until it is clear to all students.

\subsection{Learner Focus on Micro Level Features}

A large number of studies reported that novice learners have a tendency to become preoccupied with surface (micro) level features when giving and receiving PF on their texts. As a result, they are very likely to neglect more important features, such as global (macro) level features of the writing [42]. The reason that learners have such tendencies can be attributed to several different factors. One study found that such a tendency can be a result of negative transfer from past teaching, in that teachers can overemphasise the importance of micro/local features and pay very limited attention to macro/global features. Consequently, learners may find themselves assuming that they need to prioritise surface-level features [6]. Additionally, it is suggested that such tendencies can be used as an indicator of having limited linguistic skills that do not enable the learner to generate effective comments in terms of macro level [6]. Other researchers, such as Flynn [14], speculate that this could result from a lack of awareness of the used criteria which, in principle, may lead learners to be more comfortable working with what they already know.

Put differently, it can be said that learner focus on the micro level may result from receiving ineffective FB. In this regard, it has been found that the most effective FB is that given in a timely manner - at an appropriate time - and linked to explicit criteria [33]. Here the explicit criteria can be frequent, include specific details and include statements explaining what is expected to be done when completing each given task (see Appendix A for an example). As sharing criteria is very important for learner engagement in an activity [44], it is suggested that when practising PF, learners should be provided with the expected criteria in the form of an evaluation form or a checklist.

\subsection{Evaluation Forms}

It is not enough for learners to simply start commenting on the work of others without establishing common ground in terms of what is to be evaluated or looked at. One way of doing this is by providing a full form of questions that embeds criteria and guides learner attention to the desired aspects of the writing. Without such guidance, it is very likely that learners will become distracted and deal with one particular aspect while neglecting others, as is the case when learner attention is mostly shifted to surface-level features. 
The majority of those who investigated the technique stressed the importance of providing learners with evaluation forms [10]. Teachers can design their own forms that best suit the aims of their courses, or alternatively can simply adapt existing ones form the literature. In either situation, teachers have to ensure the clarity and suitability of the adapted forms for their own classrooms.

An important point to be mentioned here is that introducing the form to learners should take place at the training stage [32] as learners may need time familiarise themselves with its usage. The more practice they have, the more familiar with the criteria they are likely to get, which can lead to internalising criteria and the ability to critique without the need to refer back to the used evaluation form [6]. Detailed and clear forms can facilitate the process for learners in which they are transferred from one point to the other in a systematic manner and can allow learners to have a sense of covering wide aspects of writing features when giving PF (see Appendix A for an example). Finally, in an attempt to avoid ambiguity and learner confusion, the teacher is recommended to pilot the form before presenting it to learners, to allow reflection on the suitability of the adapted or specially designed form.

\subsection{Formative Use}

Although a number of studies have investigated the use of PF in a summative way- allowing PF to have an effect on final marks for learners - other studies have found that learners can resent being graded by fellow students and that PF can be very effective if used only formatively - with the aim of providing feedback while learning is ongoing and for this not to have an effect on final grading.

In a longitudinal study, McMahon [31] observed that there is reluctance on the part of learners to participate in $\mathrm{PF}$ practice, which leads learners to act as receivers rather than providers of FB. The study concludes that formative use can encourage learners to become more engaged in the PF process, which can also promote a greater development of critical thinking skills. Summative use, however, can be rather sensitive as some students may fear causing harm to fellow students and may not show full engagement and interest in the process. Additionally, some students may only accept teacher assessment to have an effect on their grading.

\subsection{Learner Proficiency Levels when Working Together}

Learners are normally of different linguistic levels high, mid or low levels. Furthermore, learners have reported in different contexts their concerns when working with peers whose linguistic abilities are not of an equivalent level [23]. When two peers work together and one has a higher proficiency level than the other, interaction between the two parties can be broken at any stage. In other words, a student with a low proficiency level may encounter a great deal of difficulty and require a longer time to critique a student with a higher proficiency level. Additionally, the more proficient student may not accept any judgement from the weaker. The consequence being that a negotiation of meaning may not be established which is known as the central heart of and main purpose for introducing the technique. Therefore, it is highly recommended that learners are assigned to work with peers who have similar linguistic skills.

One simple way of classifying learners into different proficiency levels is by testing their writing skills and matching those of similar levels prior to implementing PF technique. Additionally, $\mathrm{PF}$ can have different impacts on learners of different proficiency levels [28]; from this perspective, teachers who have an interest in introducing PF to particular students should take into account this fact and also refer to the findings reported in the aforementioned study.

\subsection{Associating PF with Other FB Sources}

As writing can be seen a complex process and as the numbers of students in writing classes are increasing every year, teachers may find difficulty in providing feedback to their students. In other words, teacher feedback can be rather scarce. As a result, students may have limited experience of writing features and how to develop their writing skills. In such a situation, PF can be a very helpful technique for writing teachers and lessen their burden. In addition, combining this technique with other techniques or sources of FB may yield even more positive outcomes [3, 21]. It has been noted that $P F$ is commonly used alongside teacher FB, the results of which were mostly reported to be positive [46].

In this regard, McMahon [31] found that it is possible to gain more advantages from the PF technique by associating it with self-assessment techniques, as this can motivate learners to improve their writing skills. Furthermore, Lin and Yang [26] explored the integration of PF with Wiki technology - a technology that allows co-editing of a particular piece of text electronically - in writing classes and reported a number of positive results. Another possibility is to combine computer-based FB with PF, although research on this area is somewhat limited and needs more thorough investigation. Exposing learners to different sources of FB can widen their experience and knowledge of the reviewing process.

\subsection{Pair or Group Work}

Learners can work in pairs or larger groups when commenting on texts. Each method has its own advantages and disadvantages. For example, when working in pairs, the teacher can be assured to some extent that every student 
is performing an almost equal amount of work. When working in groups, however, some students can act passively and allow other members to carry on the work on their behalf [34]. It is suggested, however, that teachers consider paying attention to group dynamics if they intend to employ the group work strategy. Another issue with pair work is that if the pair continues to work on the same task over two or more sessions, one could miss a class, putting progress on hold until both parties are present. Such problems will not be encountered when working in groups. Finally, group work allows teachers to have the possibility of the inclusion of the element of the expert in order to adapt the Vygotsky's concept of 'Zone of Proximal Development', which can be very effective in improving learner writing skills [2]. Equally, as those experts may not be available in large numbers, employing them to cover pair work would be rather difficult.

\section{Conclusion}

PF can be very useful for teachers to employ in writing classrooms. It can facilitate the development of writing skills which many learners find problematic, even over other language skills [1]. The number of students entering higher education institutions is growing every year and instructors need to employ effective techniques to allow more attention to be given to learner learning. By this means, learning is centred more on learners, rather than on the teacher, while establishing active learning situations. Before employing any technique, however, it is important that we learn how to present it to our learners in an optimal way. This can only happen if we take into account most of the suggestions given in the literature, which were mainly based on empirical studies. This paper has tackled the case of using PF in writing classrooms and attempted to present the most prominent suggestions and findings given in the literature, all with the aim of helping PF users gain more positive results from its use.

\section{Appendix A}

Evaluation checklist. (Borrowed from Alhazmi \& Schofield [3])

\section{Main Idea}

What is the overall idea?

\section{Purpose}

2.1 Is the primary purpose clear? Is the purpose to:

$\begin{array}{ll}\text { 1. } & \text { Inform? } \\ \text { 2. } & \text { Persuade? } \\ \text { 3. } & \text { Or both? }\end{array}$

\section{Content}

1. Has the writer written enough about the topic adequately?

2. Is all the information relevant to the topic?

3. Are the main ideas supported by specific examples or evidence?

4. Are there gaps in the information?

5. Is there too much information on some points?

\section{Structure of Text}

1. Does the essay have a clear introduction and a clear conclusion?

2. Is the sequence of the ideas clear - earlier to later, general to particular, thesis to supporting points, supporting points to conclusion, weaker arguments to stronger arguments? If not would it help to rearrange the order of ideas?

3. Paragraphs

a Does the essay have clear paragraph divisions?

b Is each paragraph built around one main idea?

c Do paragraph divisions match the organization of ideas in the plan?

d If not, should any of the paragraphs be:

- joined together?

- divided into smaller units?

- rearranged?

\section{Cohesions}

5.1 Do the connections between the ideas need to be made clear or explicit?

5.2 If connecting words like the ones below have been used, have they been used appropriately? Do they give the reader a sense of flow in the ideas? Or do the ideas simply read like a list?

Types of connectors

'And' type: therefore, as a result, accordingly, consequently, thus

'Or' type: in other words, to put it more simply

'But' type: however, yet, nevertheless

Other connectors include: who, which, that, when, where, because, since, although, etc.

\section{5. b. Response as Readers}

1. Does the opening paragraph make the reader want to read on?

2. Do you feel satisfied with the way the essay comes to an end?

3. Indicate your interest in your essay as a whole, using a scale from 1 to 5 (where 1 is very interesting and 5 is not interesting). 


\section{Vocabulary}

Is specialist or technical and general vocabulary accurately used?

\section{Grammar}

Do subjects and verbs agree? Are verb tenses correctly formed and correctly used? Check the correct use of prepositions, articles, adjectives, passive forms.

\section{Mechanical accuracy}

1. Punctuation: Does each sentence end with an appropriate mark of punctuation?

2. Capital letters: Are capital letters used where they are needed?

3. Spelling: Check the spelling of words that you are not sure about in a dictionary, or use the spelling checker if you are working on a word processor.

\section{REFERENCES}

[1] AbuSeileek, A. F. (2006). The Use of Word Processor for Teaching Writing to EFL Learners in King Saud University. Edu. Sci. \& Islamic Stud, 19(2), 1-15.

[2] Albesher, K. (2011). Developing the Writing Skills of ESL Learners Through Collaborative Learning Strategy. Ph.D. Thesis. Newcastle University.

[3] Alhazmi, S. H., \& Schofield, P. (2007). Enforced Revision with Checklist and Peer Feedback in EFL Writing: The Example of Saudi University Students. Scientific Journal of King Faisal University, 8(2), 223-261.

[4] Aljaafreh, A., \& Lantolf, J. P. (1994). Negative Feedback as Regulation and Second Language Learning in the Zone of Proximal Development. The Modern Language Journal, 78, 465-483.

[5] Allwright, R. L. (1975). Problems in the Study of the Language Teacher's Treatment of Learner Error. In: M. K. Burt, \& H. C. Dulay (Eds.), New Directions in Second Language Learning, Teaching and Bilingual Education (pp. 96-109). Washington, D. C.: TESOL.

[6] Alnasser, S. (2013). A New Form of Peer Feedback Technique: An Investigation into the Impact of Focusing Saudi ESL Learners on Macro Level Writing Features. Ph.D. Thesis. Newcastle University.

[7] Burt, M. K. (1975). Error Analysis in the Adult EFL Classroom. TESOL Quarterly, 9, 53-63.

[8] Burt, M. K., \& Kiparsky, C. (1972). The Gooficon: A Repair Manual for English. Massachusetts: Newbury House.

[9] Chaudron, C. (1977). A Descriptive Model of Discourse in the Corrective Treatment of Learners' Errors. Language Learning, 27(1), 29-46.
[10] Chen, C. W. (2010). Graduate Students' Self-Reported Perspectives Regarding Peer Feedback and Feedback from Writing Consultants. Asia Pacific Educ. Rev., 11, 152-158.

[11] Chu, R. (2013). Effects of Peer Feedback on Taiwanese Adolescents' English Speaking Practices and Development. $\mathrm{PhD}$. Thesis, University of Edinburgh.

[12] Denicolo, P., Entwistle, N., \& Hounsell, D. (1992). What is Active Learning? CVCP Universities' Staff Development and Training Unit.

[13] Ellis, R., Loewen, S., \& Erlam, R. (2006). Implicit and Explicit Corrective Feedback and the Acquisition of L2 Grammar. Studies in Second Language Acquisition, 28, 339-368.

[14] Flynn, E. (1982). Effects of Peer Critiquing and Model Analysis on the Quality of Biology Student Laboratory Reports. Paper presented at the annual meeting of the National Council of Teachers of English, Washington DC, USA.

[15] George, H. V. (1972). Common Errors in Language Learning: Insights from English; A Basic Guide to the Causes and Preventions of Students' Errors in Foreign Language Learning. Rowley: Newbury House Publishers.

[16] Gielen, S., Tops, L., Dochy, F., Onghena, P., \& Smeets, S. (2010). A Comparative Study of Peer and Teacher Feedback and of Various Peer Feedback Forms in a Secondary School Writing Curriculum. British Educational Research Journal, 36(1), 143-162.

[17] Hanjani, A. (2013). Peer Review, Collaborative Revision, and Genre in L2 Writing. Ph.D. Thesis, University of Exeter.

[18] Hasan, S. (2016). A Qualitative Exploration of Student Perceptions of Peer Collaboration Through the Medium of Online Short Story Writing among Turkish Public High School EFL Learners in a Social Media Environment. Ph.D. Thesis. King's College in London.

[19] Hu, G. W. (2005). Using Peer Review with Chinese ESL Student Writers. Language Teaching Research, 9, 321-342.

[20] Hyland K., \& Hyland, F. (2006a). Contexts and Issues in Feedback on L2 Writing: An Introduction. In: K. Hyland, \& F. Hyland (Eds.). Feedback in Second Language Writing: Contexts and Issues (pp. 1-19). New York: Cambridge University Press.

[21] Hyland, K., \& Hyland, F. (2006b). Feedback on Second Language Students' Writing. Language Teaching, 39, 83-101.

[22] Hyland, K., \& Hyland, F. (2006c). Interpersonal Aspects of Response: Constructing and Interpreting Teacher Written Feedback. In: K. Hyland, \& F. Hyland (Eds.). Feedback in Second Language Writing: Contexts and Issues (pp. 206-224). New York: Cambridge University Press.

[23] Kamimura, T. (2006). Effects of Peer Feedback on EFL Student Writers at Different Levels of English Proficiency: A Japanese Context. TESL Canada Journal, 23(2), 12-39.

[24] Kennedy, G. (1973). Conditions for Language Learning. In: J. W. Oller, Jr., \& J. C. Richards (Eds.), Focus on the Learner: Pragmatic Perspectives for the Language Teacher (pp. 66-82). New York: Newbury House. 
[25] Lantolf, J. P. (2000). Second Language Learning as a Mediated Process. Language Teaching, 33, 79-96.

[26] Lin, W., \& Yang, S. (2011). Exploring Students' Perceptions of Integrating Wiki Technology and Peer Feedback into English Writing Courses. English Teaching: Practice and Critique, 10(2), 88-103.

[27] Long, M. H. (1991). Focus on Form: A Design Feature in Language Teaching Methodology. In: K. D. Bot, R. Ginsberg, \& C. Kramsch (Eds.), Foreign Language Research in Cross-Cultural Perspective (pp. 39-52). Amsterdam: John Benjamins.

[28] Lundstrom, K., \& Baker, W. (2009). To Give is Better Than to Receive: The Benefits of Peer Review to the Reviewer's Own Writing. Journal of Second Language Writing, 18(1), 30-43.

[29] Lyster, R. (2004). Differential Effects of Prompts and Recasts in Form-Focused Instruction. Studies in Second Language Acquisition, 26, 399-432.

[30] Mackey, A. (2006). Feedback, Noticing and Instructed Second Language Learning. Applied Linguistics, 27(3), 405-430.

[31] McMahon, T. (2010). Peer Feedback in an Undergraduate Programme: Using Action Research to Overcome Students' Reluctance to Criticise. Educational Action Research, 18(2), 273-287.

[32] Min, H. T. (2006). The Effects of Trained Peer Review on EFL Students' Revision Types and Writing Quality. Journal of Second Language Writing, 15(2), 118-141.

[33] OECD. (2005). Formative Assessment: Improving Learning in Secondary Classrooms. Centre for Educational Research and Innovation. Paris: OECD Publication Paris, ISBN: 92-64-00739-3.

[34] Otienoh, R. (2015). Implementation of Pair Work and Group Work for Creation of Interaction Opportunities for Learners in Large Classes: The Vaibility of the Two Strategies. Journal of Education and Practice, 6(10), 171-180.

[35] Phuwichit, K. (2016). A Study of Teacher Feedback on Peer Feedback in EFL Writing and its Relation to Self-Regulation. Ph.D. Thesis. University of Southampton.
[36] Pica, T. (1996). Second Language Learning Through Interaction: Multiple Perspectives. Working Papers in Educational Linguistics, 12, 1-22.

[37] Ravem, R. (1973). Language Acquisition in a Second Language Environment. In: J. W. Oller, Jr., \& J. C. Richards (Eds.), Focus on the Learner: Pragmatic Perspectives for the Language Teacher (pp. 136-144). New York: Newbury House.

[38] Rollinson, P. (2005). Using Peer Feedback in the ESL Writing Class. ELT Journal, 59(1), 23-30.

[39] Schmidt, R. W. (1993). Awareness and Second Language Acquisition. Annual Review of Applied Linguistics, 13, 206-226.

[40] Spada, N. (1997). Form-Focused Instruction and Second Language Acquisition: A Review of Classroom and Laboratory Research. Language Teaching, 30, 73-87.

[41] Tuomey, E. (2014). Peer Feedback on Writing Essays in an Online Forum for Learners of English. Ph.D. Thesis. Lancaster University.

[42] Van Steendam, E., Rijlaarsdam, G., Sercu, L., \& Van den Berg, H. (2010). The Effect of Instruction Type and Dyadic or Individual Emulation on the Quality of Higher-Order Peer Feedback in EFL. Learning and Instruction, 20(4), 316- 327.

[43] Vygotsky, L. S. (1978). Mind in Society: The Development of Higher Psychological Processes. Cambridge: Harvard University Press.

[44] Wiliam, D., \& Leahy, S. (2007). A Theoretical Foundation for Formative Assessment. In: J. H. McMillan (Ed.), Formative Classroom Assessment: Research, Theory and Practice (pp. 29-42). New York: Teachers College Press.

[45] Wong, D. (2015). Use of Online Peer Review in ESL eNews Writing. Ph.D. Thesis. University of Bristol.

[46] Yang, M., Badger, R., \& Zhen, Y. (2006). A Comparative Study of Peer and Teacher Feedback in a Chinese EFL Writing Class. Journal of Second Language Writing, 15(3), 179-200.

[47] Zareekbatani, A. (2015). Technology and L2 Writing: EFL Student Perspectives on Electronic Feedback using Online Learning Logs. Ph.D. Thesis. University of Exeter. 